\title{
Surgical Treatment of Lung Cancer in Patients with Psychiatric Disorders: A Retrospective Study
}

\author{
Chie Ushijima1', Koji Yamazaki', Hidenori Kouso', Masakazu Katsura1, Ryo Mori' ${ }^{1}$, \\ Sadanori Takeo1, Kensuke Ishikawa² \\ ${ }^{1}$ Department of General Thoracic Surgery and Clinical Research Institute, National Hospital Organization \\ Kyushu Medical Center, Fukuoka, Japan \\ ${ }^{2}$ Department of Psychiatry, National Hospital Organization Kyushu Medical Center, Fukuoka, Japan \\ Email: chieushijimajp@yahoo.co.jp
}

Received 27 June 2016; accepted 1 August 2016; published 4 August 2016

Copyright (C) 2016 by authors and Scientific Research Publishing Inc.

This work is licensed under the Creative Commons Attribution International License (CC BY). http://creativecommons.org/licenses/by/4.0/

(c) (i) Open Access

\section{Abstract}

Background: The purpose of this retrospective study was to examine the clinical outcomes of patients with concomitant lung cancer and psychiatric disorders who underwent pulmonary resection at our institution and develop a strategy for treating such patients in the future. Methods: We retrospectively reviewed 23 patients with psychiatric disorders who underwent pulmonary resection for lung cancer at our institution between January 1984 and December 2011. Results: The study population comprised 13 men and 10 women with an average age of 67.4 years. The histological types of lung cancer included adenocarcinoma in 14 patients, squamous cell carcinoma in 4, and other types in 5. Fifteen patients were classified as having pathological TNM stage I cancer, four as having stage II, three as having stage III, and one as having stage IV. The coexisting psychiatric disorders were neurosis in eight patients, depression in seven, schizophrenia in five, dementia in two, and oligophrenia in one. Three patients were admitted without a full understanding of the operation. There were no major complications with the exception of delirium, which was seen in eight patients. None of these patients' coexisting psychiatric disorders worsened. No perioperative death occurred. Conclusions: At our institution, we cooperate closely with psychiatrists to care for surgical patients with psychiatric disorders. There is a possibility that such cooperation will reduce the frequency of previously reported complications.

\section{Keywords}

Lung Cancer Surgery, Psychiatric Disorder, Surgery, Incisions, Exposure, Techniques 


\section{Introduction}

The number of patients with psychiatric disorders who consult a psychiatrist is increasing in Japan [1]. A recent study found that lung cancer and breast cancer are more common in patients with schizophrenia [2]. Therefore, our opportunities to treat these patients are increasing. Because surgical patients with psychiatric disorders reportedly have higher complication and mortality rates, such as postoperative respiratory failure, decubitus ulcer, medical care-related infection, sepsis, deep venous thrombosis or pulmonary embolism, acute renal failure, bleeding, and stroke, [3]-[10], careful perioperative management is required. We need to monitor these patients intensively for early detection of these complications, and we try to deal with early phase. Despite this requirement, few reports have assessed the surgical outcomes in surgical patients with psychiatric disorders, especially in patients with lung cancer [11]. We conducted this study to analyze the clinical outcomes of lung cancer surgery in patients with psychiatric disorders and present a strategy for treating these patients.

\section{Patients and Methods}

The subjects comprised 23 patients with psychiatric disorders among 1387 patients who underwent pulmonary resection for lung cancer at our institution from January 1984 to December 2011. All patients were preoperatively evaluated by clinical examination with chest and abdominal computed tomography, bone scintiscan, brain computed tomography or magnetic resonance imaging, and transbronchial lung biopsy for staging. Patients were staged according to the TNM classification of the seventh edition of the International Association for the Study of Lung Cancer. Explanations of the diagnosis and surgery were simultaneously given to the patients and their families. Before admission, written consent was obtained from all patients and/or their families for inclusion of their information in our study, with an understanding that their privacy would be protected.

We retrospectively investigated the surgical outcomes including complications, the duration of drainage, and the length of hospital stay. Pulmonary air leakage was defined as air leakage that continued for more than 1 week. Delirium was defined as an acute, fluctuating change in the patient's mental state with consciousness and cognitive impairment and was diagnosed by a psychiatrist.

Some of the patients were admitted to the psychiatric ward prior to surgery as decided by the psychiatrist. Psychotropic agents were continuously administered until just prior to surgery and resumed the morning following the surgery.

Categorical variables were analyzed using Pearson's chi-squared test, and continuous variables were compared using Student's paired t-test. Statistical significance was indicated by a $p$-value of $<0.05$.

\section{Results}

The study population comprised 13 men and 10 women with an average age of 67.4 years. Their clinicopathological characteristics are summarized in Table 1 . The most common coexisting psychiatric disorder was neurosis in eight (34.8\%) patients. The other disorders were depression in seven (30.4\%) patients, schizophrenia in 5 (21.7\%), dementia in 2 (8.7\%), and oligophrenia in 1 (4.3\%). Three patients had low understanding of the operation (low-understanding patients; two with dementia, one with oligophrenia). Twelve patients were admitted to the psychiatric ward, including the five patients with schizophrenia. The details of the histological types and pathological TNM stages were similar to those of patients without psychiatric disorders (data not shown).

Table 2 shows the differences in operative data between the patients with psychiatric disorders and those without psychiatric disorders (control group). The types of operations performed in the patients with psychiatric disorders included lobectomy $(n=16,70.0 \%)$, segmentectomy $(n=2,8.7 \%)$, and wedge resection $(n=5$, $21.7 \%)$. These proportions of surgical procedures were similar to those in the control group. For the patients with psychiatric disorders, indications for surgery were determined based on their physiological and oncological conditions. The operation time and blood loss did not differ between the two groups ( $p=0.2608$ and 0.4336 , respectively). There were no major complications with the exception of delirium, which was seen in eight patients. The incidence of delirium in patients with psychiatric disorders was significantly higher than that in patients without psychiatric disorders $(p<0.01)$. Aspiration pneumonia developed in one patient with delirium. None of the patients' coexisting psychiatric disorders worsened. No perioperative death occurred.

Table 3 summarizes the data of the eight patients who developed postoperative delirium. The mean age of these patients was 72.3 years, which was significantly higher than that of patients without delirium (64.8 years; $p=0.036)$. The incidence of delirium was significantly high among patients with neurosis $(\mathrm{n}=5,62.5 \%$; $p=$ 
Table 1. Background factors of patients with phychiatric disorders $(n=23)$.

Age (average)
Sex (male/female)

Medical comorbidities

Type of disorders

Understanding for operation (with/without)

Pathological diagnosis (Adenoca./Squamous cell ca./Others)

Pathological stage (I/II/III/IV)
$67.4(50-79)$

$13 / 10$

Diabetes
Hypertension
Angina
Hyperlipidemia
COPD
Collagen disease

Neurosis
Depression
Schizophrenia
Dementia
Oligophrenia

4

2

1

1

1

1

8

7

5

2

$20 / 3$

$14 / 4 / 5$

$15 / 4 / 3 / 1$

12

Admitted to the psychiatrict ward (Neurosis 4/Depression 2/Schizophrenia 5/Oligophrenia 1)

Table 2. Operation and postoperative complication.

\begin{tabular}{ccc}
\hline & With psychiatric disorders $(\mathrm{n}=23)$ & Without psychiatric disorders $(\mathrm{n}=1364)$ \\
\hline Type of operation & & \\
\hline Wedge resection & $5(21.7 \%)$ & $184(13.5 \%)$ \\
Segmentectomy & $2(8.7 \%)$ & $107(7.8 \%)$ \\
Lobectomy & $17(70.0 \%)$ & $1073(78.7 \%)$ \\
Operation time (min) & $201(85-277)$ & $181(25-780)$ \\
Blood loss (g) & $156($ little-536) & $242($ little-8500) \\
Complications & & \\
Delilium & $8(35 \%)$ & $19(1 \%)$ \\
Pneumonia & $1(4 \%)$ & $23(2 \%)$ \\
Pulmonary fistula & $1(4 \%)$ & $130(10 \%)$ \\
Post-operative hospital stay (days) & $17(4-60)$ & $22(2-89)$ \\
\hline
\end{tabular}

Table 3. Case of delilium.

\begin{tabular}{|c|c|c|c|}
\hline & With delilium $(\mathrm{n}=8)$ & Without delilium (n = 15) & $p$ \\
\hline Age & $72.3(62-79)$ & $64.8(50-79)$ & 0.036 \\
\hline Sex (male/female) & $6 / 2$ & $7 / 8$ & \multirow{6}{*}{0.04} \\
\hline \multicolumn{4}{|l|}{ Type of disorder } \\
\hline Neurosis & 5 & 3 & \\
\hline Depression & 0 & 7 & \\
\hline Schizophrenia & 1 & 4 & \\
\hline Dementia & 1 & 1 & \\
\hline Oligophrenia & 1 & 0 & \\
\hline Admitted to the psychiatric ward & $6^{*}$ & 2 & \\
\hline Without insight for operatin & 2 & 2 & \\
\hline Duration for drainage (days) & $6(2-15)$ & $5(2-8)$ & \\
\hline
\end{tabular}

"(Neurosis 3 /Dementia 1/Schizophrenia 1/Oligophrenia 1).

0.04). Two of three of the low-understanding patients developed delirium. Six of the eight patients who developed delirium were admitted to the psychiatric ward. The duration of drainage was similar in both groups (6 and 5 days among patients with and without delirium, respectively). Four patients required restraint based on the psychiatrist's judgment, and six patients required medication to control the delirium. All patients recovered from 
the delirium uneventfully.

\section{Discussion}

Surgical patients with psychiatric disorders reportedly have higher postoperative complication and mortality rates. Liao et al. reported that surgical patients with schizophrenia had significantly (nearly 2.5 -fold) higher 30-day postoperative complication and mortality rates [8]. Commonly reported complications are postoperative respiratory failure (odds ratio [OR], 1.96; 95\% confidence interval [CI], 1.67 - 2.30), decubitus ulcer (OR, 1.43; 95\% CI, 1.36 - 1.51), medical care-related infection (OR, 1.19; 95\% CI, 1.08 - 1.30), sepsis (OR, 1.59; 95\% CI, 1.25 - 2.02), deep venous thrombosis or pulmonary embolism (OR, 1.23; 95\% CI, 1.13 - 1.35), acute renal failure (OR, 3.92; 95\% CI, 2.25 - 6.81), bleeding (OR, 1.27; 95\% CI, 1.05 - 1.54), and stroke (OR, 1.39; 95\% CI, 1.18 - 1.64) [8] [10]. Two major reasons for the higher complication rates among this population have been postulated. First, previous studies have found that patients who use antipsychotics, such as those with schizophrenia, face significantly increased risks of cardiovascular disease (hazard ratio [HR], 1.43; 95\% CI, 1.22 - 1.69) [12] [13], diabetes (OR, 1.81; 95\% CI, 1.61 - 2.03) [14], metabolic syndrome (male OR, 2.00; female OR, 2.13) [15], and stroke (male HR, 1.64, $p<0.001$; female HR, 2.87, $p<0.001$ ) [16] and a resultant increased risk of death. Surgeons must manage these patients as a high-risk group. Furthermore, interactions among analgesics, anesthetics, and patients' regular psychotropic medications may also contribute to the higher rates of adverse outcomes [17]. Antipsychotics may be a cause of pain insensitivity that can delay diagnosis and treatment [17]. Second, some reports have suggested that poor communication between patients and medical staff members may lead to delayed diagnosis and treatment [4] [18]. On the surgical floor, surgeons, nurses, and other health care professionals may not be experienced in caring for the special needs of these patients. Further, the health care team members managing patients with psychiatric disorders may not contribute to the findings of the increased risk of surgical patients with psychiatric disorders. It may be necessary for the two teams to collaborate.

We analyzed the clinical outcomes of 23 patients with psychiatric disorders who underwent surgery for lung cancer. There were no major complications with the exception of delirium, which was seen in eight patients. In this study, three patients had diabetes mellitus and one had angina. Postoperative management was not difficult. The incidence of delirium was significantly high in patients with neurosis (five of eight patients, 62.5\%; $p=$ 0.04), and two of three low-understanding patients developed delirium. Six of the eight patients with delirium were admitted to the psychiatric ward. However, there is no evidence that the psychiatric disorders were risk factors for delirium in this study. The present results must indicate the involvement of different factors. One possibility is that the high incidence of delirium in patients with neurosis was due to the minor tranquilizer that they received. The average age of patients with delirium was significantly higher than that of patients without delirium (72.3 vs. 64.6 years, respectively; $p=0.036$ ) and included two of the three low-understanding patients. Old age and cognitive disorders are two risk factors for postoperative delirium [19].

At our institution, a psychiatrist provides total support during the perioperative management of patients with psychiatric disorders. This support includes management of patients' regular psychotropic medications, patient communication, and correspondence regarding mental alterations. This type of cooperation may help to reduce the frequency of previously reported complications.

\section{Conclusions}

This study has limitation. We used retrospective data from medical records of our institutes without detailed patients' information of the psychiatric disorder, laboratory and physical data. Despite this limitation, we believe that these results suggest methods to effectively deal with such patients when they are encountered in the future.

In conclusion, for patients with psychiatric disorders, including cognitive disorders, cooperation between the surgeon and psychiatrist is essential to avoid certain risks.

\section{Disclosure Statement}

The authors disclose no financial or personal relationships with other people or organizations that could inappropriately influence the present work.

\section{References}

[1] Ministry of Health (Accessed 21 Oct 2013) Labour and Welfare. (In Japanese) 
http://www.mhlw.go.jp/kokoro/speciality/data.html

[2] Bushe, C.J. and Hodgson, R. (2010) Schizophrenia and Cancer: In 2010 Do We Understand the Connection? Canadian Journal of Psychiatry Revue canadienne de psychiatrie, 55,761-767.

[3] Fulop, G., Strain, J.J., Fahs, M.C., Schmeidler, J. and Snyder, S. (1998) A Prospective Study of the Impact of Psychiatric Comorbidity on Length of Hospital Stays of Elderly Medical-Surgical Inpatients. Psychosomatics, 39, 273-280. http://dx.doi.org/10.1016/S0033-3182(98)71344-1

[4] Rocha, F.F., Soares, F.M., Correa, H., Rocha, R.F. and Teixeira, A.L. (2007) Increased Surgical Morbidity of Psychiatric Patients Submitted to Appendectomy. Revista Brasileira de Psiquiatria, 29, 92-93. http://dx.doi.org/10.1590/S1516-44462007000200024

[5] Li, Y., Glance, L.G., Cai, X. and Mukamel, D.B. (2008) Adverse Hospital Events for Mentally Ill Patients Undergoing Coronary Artery Bypass Surgery. Health Services Research, 43, 2239-2252. http://dx.doi.org/10.1111/j.1475-6773.2008.00875.x

[6] Abrams, T.E., Vaughan-Sarrazin, M. and Rosenthal, G.E. (2010) Influence of Psychiatric Comorbidity on Surgical Mortality. Archives of Surgery, 145, 947-953. http://dx.doi.org/10.1001/archsurg.2010.190

[7] Copeland, L.A., Zeber, J.E., Pugh, M.J., Mortensen, E.M., Restrepo, M.I. and Lawrence, V.A. (2008) Postoperative Complications in the Seriously Mentally Ill: A Systematic Review of the Literature. Annals of Surgery, 248, 31-38. http://dx.doi.org/10.1097/SLA.0b013e3181724f25

[8] Liao, C.C., Shen, W.W., Chang, C.C., Chang, H. and Chen, T.L. (2013) Surgical Adverse Outcomes in Patients with Schizophrenia: A Population-Based Study. Annals of Surgery, 257, 433-438. http://dx.doi.org/10.1097/SLA.0b013e31827b9b25

[9] Daumit, G.L., Pronovost, P.J., Anthony, C.B., Guallar, E., Steinwachs, D.M. and Ford, D.E. (2006) Adverse Events during Medical and Surgical Hospitalizations for Persons with Schizophrenia. Archives of General Psychiatry, 63, 267-272. http://dx.doi.org/10.1001/archpsyc.63.3.267

[10] Khaykin, E., Ford, D.E., Pronovost, P.J., Dixon, L. and Daumit, G.L. (2010) National Estimates of Adverse Events during Nonpsychiatric Hospitalizations for Persons with Schizophrenia. General Hospital Psychiatry, 32, 419-425. http://dx.doi.org/10.1016/j.genhosppsych.2010.04.006

[11] Obuchi, T., Okabayashi, K., Imakiire, T., Yoneda, S. and Iwasaki, A. (2014) The Outcomes of Surgery in Lung Cancer Patients with Schizophrenia. Surgery Today, 44, 855-858. http://dx.doi.org/10.1007/s00595-013-0599-0

[12] Callaghan, R.C., Boire, M.D., Lazo, R.G., McKenzie, K. and Cohn, T. (2009) Schizophrenia and the Incidence of Cardiovascular Morbidity: A Population-Based Longitudinal Study in Ontario, Canada. Schizophrenia Research, 115, 325332. http://dx.doi.org/10.1016/j.schres.2009.07.018

[13] Laursen, T.M. and Nordentoft, M. (2006) Heart Disease Treatment and Mortality in Schizophrenia and Bipolar Disorder-Changes in the Danish Population between 1994 and 2006. Journal of Psychiatric Research, 45, 29-35. http://dx.doi.org/10.1016/j.jpsychires.2010.04.027

[14] Chien, I.C., Hsu, J.H., Lin, C.H., Bih, S.H., Chou, Y.J. and Chou, P. (2009) Prevalence of Diabetes in Patients with Schizophrenia in Taiwan: A Population-Based National Health Insurance Study. Schizophrenia Research, 111, 17-22. http://dx.doi.org/10.1016/j.schres.2009.04.003

[15] Sugawara, N., Yasui-Furukori, N., Sato, Y., Umeda, T., Kishida, I., Yamashita, H., et al. (2010) Prevalence of Metabolic Syndrome among Patients with Schizophrenia in Japan. Schizophrenia Research, 123, 244-250. http://dx.doi.org/10.1016/j.schres.2010.08.030

[16] Lin, H.C., Hsiao, F.H., Pfeiffer, S., Hwang, Y.T. and Lee, H.C. (2008) An Increased Risk of Stroke among Young Schizophrenia Patients. Schizophrenia Research, 101, 234-241. http://dx.doi.org/10.1016/j.schres.2007.12.485

[17] Kudoh, A. (2005) Perioperative Management for Chronic Schizophrenic Patients. Anesthesia \& Analgesia, 101, 18671872. http://dx.doi.org/10.1213/01.ANE.0000184123.67853.86

[18] Cooke, B.K., Magas, L.T., Virgo, K.S., Feinberg, B., Adityanjee, A. and Johnson, F.E. (2007) Appendectomy for Appendicitis in Patients with Schizophrenia. The American Journal of Surgery, 193, 41-48. http://dx.doi.org/10.1016/j.amjsurg.2006.06.034

[19] Michaud, L., Bula, C., Berney, A., Camus, V., Voellinger, R., Stiefel, F., et al. (2007) Delirium: Guidelines for General Hospitals. Journal of Psychosomatic Research, 62, 371-383. http://dx.doi.org/10.1016/j.jpsychores.2006.10.004 


\section{Submit or recommend next manuscript to SCIRP and we will provide best service for you:}

Accepting pre-submission inquiries through Email, Facebook, LinkedIn, Twitter, etc.

A wide selection of journals (inclusive of 9 subjects, more than 200 journals)

Providing 24-hour high-quality service

User-friendly online submission system

Fair and swift peer-review system

Efficient typesetting and proofreading procedure

Display of the result of downloads and visits, as well as the number of cited articles

Maximum dissemination of your research work

Submit your manuscript at: http://papersubmission.scirp.org/ 